\title{
Effects of nutrient solution concentration on plant growth and phytochemical accumulation in substrate-grown spinach
}

Acta
Horticulturae
Home

Search

Authors: $\quad$ R.M.A. Machado, C. Malta, I. Alves-Pereira, R.M.A. Ferreira

Keywords: Spinacia oleracea L., soilless system, leafy vegetables, salinity, nitrate, total phenols, vitamin B2

DOI:

10.17660/ActaHortic.2021.1305.65

Abstract:

The effect of the electrical conductivity of a complete nutrient solution and of the spinach cultivar (Spinacia oleracea L. 'Regia' and 'Manatee') on the growth, nitrates, total phenols compounds, riboflavin, ascorbic acid, and photosynthetic pigments contents, antioxidant power (FRAP, DPPH) and ascorbate peroxidase activity was evaluated. Soil-blocked spinach seedlings (five seedlings per block) were transplanted (on 25 January 2018) at 18 days after emergence to Styrofoam planting boxes $(100 \mathrm{~cm}$ long $\times 25 \mathrm{~cm}$ wide $\times$ $10 \mathrm{~cm}$ high) filled with $14 \mathrm{~L}$ of substrate. Each planting box was irrigated daily by drip and fertilized with nutrient solution. The nutrient solution adopted had two concentrations of nutrients, corresponding to an EC of $1.2 \pm 0.2$ and $1.7 \pm 0.2 \mathrm{dS} \mathrm{m}^{-1}$. Fresh yield was not to be found affected by the EC of the nutrient solution or by the cultivar. Shoot biomass percentage and leaf-blade $\mathrm{NO}_{3}$ increased as the $\mathrm{EC}$ of the nutrient solution increased. Leaf-blade riboflavin was found to be affected by the interaction between EC and cultivar,

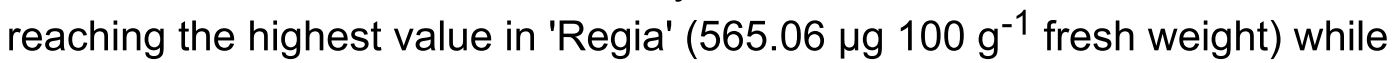
EC $1.2 \mathrm{dS} \mathrm{m}^{-1}$. Nutrient solution EC was not found to have an influence on the content of total phenols compounds, ascorbic acid, chlorophyll a and b, carotenoids and ascorbate peroxidase. The cultivar was found to have an influence on nitrates and photosynthetic pigments content and ascorbate peroxidase activity.

- Article - full text (enhanced PDF format, 658744 bytes)

Article sharing - repository deposits - copyright questions

- References

How to cite this article

- Translate

Selecionar idioma $\quad \checkmark$

Tecnologia do Google Tradutor

Download Adobe Acrobat Reader (free software to read PDF files)

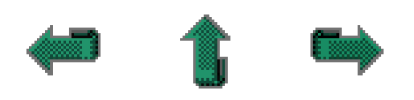

URL www.actahort.org Hosted by KU Leuven @ ISHS 
